\title{
O ALUNO SOB MEDIDA: OS TESTES PSICOLÓGICOS E EDUCACIONAIS COMO TECNOLOGIA
}

\author{
ODAIR SASS
}

\begin{abstract}
RESUMO: Discute-se a relação entre a psicologia e a estatística, no campo educacional, procurando evidenciar que tal relação não se esgota com a explicação do progresso científico inexorável; antes, ela é indissociável da realização objetiva da racionalidade tecnológica, característica da sociedade industrial e administrada. Essa perspectiva é explorada por meio da psicotécnica, primeiramente, recorrendo a um momento importante do desenvolvimento da noção de inteligência, exemplificada pela teoria bifatorial de Spearman; depois, por meio da aplicação de testes psicológicos e educacionais, na escola primária brasileira, conforme os educadores Isaias Alves e Lourenço Filho.
\end{abstract}

Palavras-chave: Psicologia. Estatística. Testes. Tecnologia. Educação.

\section{CUSTOM-MADE STUDENTS: PSYCHOLOGICAL AND EDUCATIONAL TESTS AS TECHNOLOGY}

\begin{abstract}
This paper discusses the relationship between psychology and statistics in the field of education. It shows that such relation is not limited to the explanation of the inexorable scientific progress. Rather, it cannot be dissociated from the objective achievement of technological rationality, which is characteristic of the industrial and administered society. This perspective is first explored through psychotechnics, using an important moment of the development of the intelligence concept exemplified by the bi-factorial theory of Spearman. Then, the text resorts to the application of psychological and educational tests in Brazilian primary schools, as promoted by two educators, Isaias Alves and Lourenço Filho.
\end{abstract}

Key words: Psychology. Statistics. Tests. Technology. Education.

Doutor em Psicologia Social e professor do Programa de Estudos Pós-graduados em Educação: História, Política, Sociedade, da Pontifícia Universidade Católica de São Paulo (PUC-SP). E-mail: odairsass@pucsp.br 


\section{L'ÉTUDIANT SUR MESURE: LES TESTS PSYCHOLOGIQUES ET ÉDUCA-} TIONNELS COMME TECHNOLOGIE

RÉSUMÉ: Cet article discute le rapport entre la psychologie et les statistiques dans le champ de l'éducation pour montre qu'il ne s'épuise pas dans l'explication du progrès scientifique inexorable; bien plutôt, elle est indissociable de la réalisation objective de la rationalité technologique, caractéristique de la société industrielle et administrée. Cette perspective est tout d'abord explorée au moyen de la psychotechnique grâce à un moment important du développement de la notion d'intelligence, exemplifiée par la théorie bifactorielle de Spearman, puis au moyen de tests psychologiques et éducationnels, à l'école primaire brésilienne, en accord avec les éducateurs Isaias Alves et Lourenço Filho.

Mots-clés: Psychologie. Statistiques. Tests. Technologie. Éducation.

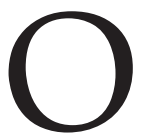

título deste artigo é uma alusão à conferência proferida por Edouard Claparède (1873-1940), em 1901, L'école sur mesure ("A escola sob medida"). Quanto à expressão "escola sob medida", esclarece o autor: "Nem se precisa dizer que estas palavras significam apenas uma escola adaptada à mentalidade de cada um, uma escola que se acomode tão perfeitamente aos espíritos, quanto uma roupa ou um calçado sob medida o fazem para o corpo ou para o pé" (Claparéde, 1973, p. 87); uma escola que admite, descobre, diagnostica as aptidões individuais e o interesse do aluno como propulsores de seu desenvolvimento, organizada de modo a não obstruir as capacidades e riquezas latentes de cada um. Claparède argumenta ainda, na referida conferência, que as reformas educacionais devem criar tal escola, como uma incumbência do Estado.

É indubitável que esse psicólogo e educador suíço foi, junto com tantos outros de seus contemporâneos, um defensor da escola pública, a instituição social par excellence para formar o homem necessário à sociedade industrial ascendente e em expansão, de modo mais acentuado desde o final do século xIx. Note-se que o interesse pela psicologia da criança e suas relações com a educação não é uma decorrência de um desenvolvimento científico natural motivado estritamente por questões epistemológicas ou metodológicas, antes deve ser associado às exigências de uma sociedade industrial ascendente, pois:

Foi nos países industrializados que se acentuou o interesse pela psicologia da criança e suas aplicações à educação. Está claro que tal interesse não resulta de um desenvolvimento puramente intelectual e depende, largamente, das novas condições de vida e de fatores ideológicos muito importantes. (Leite, 2008, p. 321-322)

Os fatores explicativos da emergência da psicologia infantil e educacional, conforme Dante Moreira Leite (2008) sistematiza-os, em 1967, referem-se à deterioração da vida familiar, condições inumanas de trabalho a que as crianças eram 
submetidas, regulamentação e posterior proibição do trabalho infantil, criação de novas profissões e ocupações pela indústria, adoção de medidas de higiene e redução da mortalidade infantil, expansão da escolaridade para a população, gradativa para cada faixa etária (Leite, 2008).

De par com reconhecimento da relevância da obra do autor para o desenvolvimento da psicologia da criança e do fortalecimento da relação entre a psicologia e a educação, pretende-se evidenciar que a premissa de "adaptação da escola à mentalidade de cada um", adotada como princípio geral, inclusive na educação brasileira, não é mais verdadeira do que a premissa inversa, qual seja: a "adaptação da mentalidade de cada um à escola". Por isso, à escola sob medida contrapõe-se, neste estudo, o aluno sob medida, não com o intuito de complementar a tese da escola ativa, mas, antes, de refutá-la, apontando suas contradições.

Enfatiza-se, a título de delimitação, apenas um dos meios elaborados, por educadores de matizes distintos, para tornar o aluno sob medida: os testes psicológicos e educacionais padronizados, instrumentos básicos da psicometria e da psicotécnica, impulsionados substancialmente no início do século passado.

A psicometria é discutida como conhecimento científico da psicologia, deliberadamente aplicado para exercer o controle social do sujeito, e o conjunto de estímulos ou itens aos quais o indivíduo deve responder - o teste propriamente dito - constitui um dos fatores. Especificamente, entende-se a psicometria como um elemento importante da tecnologia - aqui admitida como modo de produção, "como a totalidade dos instrumentos, dispositivos e invenções que caracterizam a era da máquina, é assim, ao mesmo tempo, uma forma de organizar e perpetuar (ou modificar) as relações sociais, uma manifestação do pensamento e dos padrões de comportamento dominantes, um instrumento de controle e dominação" (Marcuse, 1999, p. 73) - e um componente decisivo da racionalidade tecnológica, típica da sociedade industrial e administrada, visto que a formação de indivíduos adaptados a tal racionalidade constitui também um fator tecnológico e condição para pôr em funcionamento e garantir a reprodução do sistema social.

A exposição cinge-se a apontar (i) com brevidade o desenvolvimento do conceito de inteligência e os seus nexos com a educação, mediante a teoria bifatorial de Spearman. A inclusão da doutrina eclética de Spearman visa a robustecer a hipótese de que, para além de ser considerada uma resultante necessária ou inevitável da evolução epistemológica das descobertas científicas que pretendem superar as teorias precedentes, a teoria bifatorial da inteligência exemplifica, mais do que aquelas que a antecederam, o vínculo da noção psicológica de inteligência ao princípio do desempenho, característico da sociedade unidimensional (Marcuse, 1979); (ii) a inserção da mensuração psicológica e da estatística na educação brasileira; (iii) os 
testes de inteligência como uma importante aplicação da psicometria ao estudo do indivíduo, tomando como referência a apropriação das provas de nível mental, realizadas no Brasil, tal como as apreenderam Isaias Alves (1888-1968), com objetivo de utilizar a ciência psicológica para reorganizar a escola básica brasileira, nos anos de 1930 (Alves, 1934) e a variante educacional das provas padronizadas elaborada por Lourenço Filho (1897-1970): os "testes ABC para a verificação da maturidade necessária à aprendizagem da leitura e da escrita", na década de 1930, largamente aplicados às crianças ingressantes da escola primária brasileira e outros países americanos e europeus (Lourenço Filho, 2008).

Sustenta-se a hipótese de que as provas psicológicas e educacionais aplicadas à educação estão relacionadas muito mais à racionalidade tecnológica predominante na sociedade industrial do que a uma suposta evolução epistemológica natural que as vincula como uma decorrência inevitável do progresso científico e da aproximação entre a psicologia e as ciências físico-matemáticas.

\section{A crítica de Spearman ao conceito de inteligência e a teoria dos dois fatores}

Antecede a apropriação e difusão das provas padronizadas, psicológicas e educacionais, no Brasil, uma discussão circunstanciada sobre o conceito de inteligência, bem como o esforço de operacionalizá-lo, tal como estatísticos e psicólogos destacados propuseram nos primórdios do século passado. Em particular, vale a pena repor o impulso decisivo para a difusão da noção de inteligência e suas aplicações em distintas áreas da atividade social, a exemplo da educação e da indústria, proporcionado pela teoria bifatorial elaborada por Charles Spearman (1863-1945), publicada originalmente em 1904 (Spearman, 1904) e desenvolvida especialmente em The abilities of man $(1927 / 1954){ }^{1}$

A teoria dos dois fatores toma como referência a crítica encetada pelo autor ao uso confuso e equivocado da noção de inteligência no início do século xx, nos seguintes termos:

Em conjunto, a crônica da moderna "inteligência" resulta dramática. O primeiro ato mostra-a em rápida ascensão até alturas insuspeitadas. Mas, no segundo, começa-se a ouvir as primeiras notas críticas que não tardam em multiplicar-se, formando um insistente coro hostil. Os defensores mais entusiastas da inteligência perdem a fé nela (...). No último ato, a verdade aparece com toda claridade: o nome não tem, na realidade, nenhum significado definido; não é se não uma palavra suposta, aplicada, sem discriminação, a toda classe de coisas. (Spearman, 1954, p. 44)

A veemência da crítica decorre, de acordo com o seu autor, das divergências quanto à natureza da inteligência, visto que uns - a exemplo de Spencer, Stern, 
Claparède - consideram-na de natureza biológica, ao defini-la essencialmente como adaptação consciente a situações novas, ao passo que outros - Thorndike, Dewey, Mead - vinculam-na à pedagogia, enunciando-a como capacidade do sujeito para aprender; outros, ainda, denominados por Spearman de escolásticos, concebem a inteligência como a operação do pensamento realizada em termos abstratos e universais. Sem contar, complemente-se, a objeção séria à época de que era impossível, ou um esforço inútil, pretender medir algo como a inteligência humana. Disso tudo, o que se observa é a divergência.

Dessa crítica à noção de inteligência vale sumariar os seguintes aspectos: 1) a generalização indevida do termo é considerada "um dos obstáculos teoricamente mais perniciosos" por causa do "uso da palavra sem nenhuma ideia definida por detrás dela" (Spearman, 1954, p. 355); 2) associa-se ao uso abusivo do termo outro obstáculo, "talvez mais danoso, todavia na prática, a tendência incontrolável a supor que termos tais como 'atenção', 'combinação', 'análise', 'escala de associação', 'coordenação viso-manual' etc. representavam outras tantas unidades funcionais ou de conduta" (idem, ibid.); 3) paralelamente aos problemas decorrentes desses dois aspectos, "corria a pseudoexplicação de que os testes de inteligência de uma pessoa mediam um 'nível', uma 'média', ou uma 'amostra' de suas habilidades, em que pese essa medição ser considerada inconcebível, ou não ter sido tentada jamais de forma autêntica" (idem, ibid.). Cabe esclarecer que esta última objeção do autor refere-se, provavelmente, ao fato de que as palavras "nível", "média" e "amostra", tal como eram então utilizadas, careciam de significado científico, uma vez que, para falar em "nível" de inteligência de uma pessoa, é indispensável que haja um ponto de referência em relação a qual "nível" é medido; do mesmo modo, a ideia de uma inteligência média de uma pessoa pressupõe que todos os valores possíveis dessa característica estejam disponíveis; o mesmo argumento é válido para a noção de "amostra" de habilidades, à medida que supõe a existência de um conjunto completo de habilidades da pessoa, de sorte a atribuir um significado plausível ao termo.

Em face dessas objeções, a posição propugnada por Spearman, por ele denominada de doutrina eclética ou teoria dos dois fatores da inteligência, pretende extrair o conteúdo de verdade das teorias divergentes (Spearman, 1954, p. 80 e ss). Para os nossos propósitos, basta apresentar uma observação acerca dessa teoria: em primeiro lugar, vale dizer que a base da definição de inteligência, nos termos de Spearman, é de base estatística, especificamente, fundamentada mediante a obtenção de correlações entre as habilidades psicológicas; assim, espera-se, por exemplo, que o domínio em língua portuguesa - digamos, gramática e redação - seja correlacionado positivamente ao desempenho verbal, isto é, sujeitos que obtenham um desempenho alto em uma habilidade tendem a obter desempenho igualmente alto na outra 
característica e, reciprocamente, desempenhos baixo ou mediano em uma tende a ser acompanhado de desempenhos baixo e mediano na outra.

A consequência lógica dessa definição é dupla, pois, por um lado, é preciso admitir que, caso seja obtida uma correlação estatística significante entre duas variáveis psicológicas, há de haver um fator comum a ambas e, por outro, é forçoso admitir que, ao medirem características psíquicas distintas, cada uma delas deve conter um fator específico. Caso contrário, estariam medindo a mesma coisa e não caberia então pretender distingui-las. No exemplo exposto, pode-se inferir que o fator comum ou geral que "explica" a correlação entre domínio em língua portuguesa e desempenho verbal deve ser relativo à "linguagem", denominação arbitrária porque, claro está, pela definição um fator não tem existência material, é antes uma inferência do pesquisador. Ao mesmo tempo, deve-se admitir como resultante lógica que tanto o domínio em língua portuguesa, quanto o desempenho verbal contêm um fator específico a cada uma das duas habilidades.

Abstraindo a formulação propriamente matemática e estatística, a teoria bifatorial considera que a inteligência pode ser subdividida em duas partes: uma constituída por um fator comum ou geral a duas ou mais habilidades e a outra, constituída por um fator específico. Nos termos de seu proponente:

A uma parte tem-se chamado de "fator geral", designado com a letra g: é assim chamado porque, embora varie livremente de um indivíduo a outro, permanece inalterável para um mesmo indivíduo, com respeito a todas as demais aptidões correlacionadas. A segunda parte é chamada de "fator específico" e designada com a letra e. Não só varia de um indivíduo para outro, mas varia em um mesmo indivíduo para as distintas aptidões. (Spearman, 1954, p. 82)

Como a relação entre $g$ e $e$ não é elementar, vale acompanhar o raciocínio que se segue:

Posto que g é somente um "fator" das medições da capacidade, devemos inferir que tais medições devem conter também algum outro elemento constitutivo ou fator. É, pois, este outro fator que temos chamado e.

O primeiro grupo de características a ele concernente refere-se às suas correlações. Pois bem: quaisquer que sejam as condições, [o fator e] não apresenta nenhuma correlação com g. Mais ainda... cada e é independente de todos os demais fatores, a menos que as operações exigidas por dois fatores sejam muito semelhantes entre si. (Spearman, 1954, p. 358)

O argumento é relativamente simples: os fatores $g$ e $e$ são distinguíveis, sendo o primeiro referente ao componente geral da inteligência e o segundo associado a cada aptidão ou habilidade em pauta. Tal distinção é tanto teórica quanto é verificável por intermédio de correlações efetivamente calculadas, para pares de habilidades 
específicas; ao mesmo tempo, como é específico, um fator $e$ somente será correlacionado empiricamente com outro fator específico caso as operações necessárias para a consecução das atividades em tela sejam as mesmas ou muito próximas entre si. Apenas para registro, essa questão relaciona-se diretamente com a transferência de treino, amplamente discutida a propósito das teorias da aprendizagem, a partir do conexionismo de Edward Thorndike (cf. Garret, 1974).

Ler e escrever, por exemplo, são habilidades distintas, embora ambas possam ser incluídas em um fator geral que podemos denominar, digamos, de "alfabetização", além de que a provável correlação positiva entre elas - espera-se que, em geral, a pessoa com bom domínio de leitura tenha também boa escrita, apesar de que isso empiricamente nem sempre ocorra - decorre do fato de ambas as habilidades exigirem operações similares (simbolização, reconhecimento do alfabeto, domínio das regras gramaticais, entre outras), a par de operações exclusivas, pois uma coisa é escrever, outra é ler. Daí, a conclusão da teoria dos dois fatores de que o fator geral é independente dos fatores específicos; independência no sentido estatístico, isto é, a correlação entre os fatores, geral e específico, é nula.

Uma consequência dessa teoria é que a singularidade de cada aptidão passa a ser uma objeção à noção de inteligência como uma característica apenas essencialmente geral, conforme as ponderações já apresentadas. Nos termos de Spearman (1954, p. 358-359):

\footnotetext{
Mas, esse fato lança por terra de imediato todas as supostas faculdades funcionais (tais como, por exemplo, a de "atenção"), junto com todos os "perfis" em que haviam sido incluídas estas faculdades. Põe-se de manifesto, ao mesmo tempo, a ineficácia da maioria dos testes industriais correntes para as "habilidades específicas". Com efeito, para que um teste desse tipo fosse realmente válido teria que assemelhar-se muito estreitamente à verdadeira operação industrial em questão. (Grifos do original)
}

Pode-se concluir, então, que a inteligência não é uma aptidão geral e as habilidades específicas, incluindo aquelas exigidas pela indústria, devem ser semelhantes às operações determinadas pela maquinaria. Tal concepção do fator específico, como bem sintetiza o apresentador do livro de Charles Spearman, J. Bernstein (1954, p. 14-15):

É um fator quantitativo... variável tanto de uma a outra habilidade de um mesmo indivíduo, como de um a outro indivíduo. Portanto, e é próprio de cada habilidade particular e não depende nem se correlaciona com g, nem com outros e. Qualitativamente os e são as máquinas, dispositivos ou instrumentos (engines) por meio dos quais atua e opera a energia mental (g). A cada habilidade corresponde uma "engine".

Dois comentários são então pertinentes: 1) a crítica de Spearman à acepção de inteligência como adaptação biológica, tal como a que endereçou a Claparède, Spencer 
e Stern, serviu-lhe de base para adaptar a inteligência à indústria, mais especificamente, como bem escreveu Bernstein, converter as próprias operações mentais como máquinas ou "engines"; 2) é lícito considerar que a psicologia passa, assim, a ser entendida como tecnologia; note-se que não se trata de um efeito da tecnologia sobre o psiquismo, mas de admiti-lo como "muito semelhante à máquina", como tecnologia.

É razoável concluir, portanto, que a crítica científica realizada por Spearman contribui para o esclarecimento do conceito de inteligência, sob a perspectiva psicológica, de par com a sua adaptação às exigências da indústria do século $\mathrm{xx}$, em acelerado processo de desenvolvimento. A ciência psicológica dispõe os conhecimentos que obtém para fortalecer a racionalidade tecnológica da sociedade de base industrial e, com isso, a ideologia imanente a essa racionalidade.

A rigor, Spearman apresenta a partição da inteligência em dois fatores, sob a forma de um teorema matemático que, segundo ele, "é perfeitamente geral: sua aplicação não está, de modo algum, limitada à psicologia" (Spearman, 1954, p. 82, nota 2). Essa observação articula-se às anteriores à medida que evidencia um momento importante da elaboração do método estatístico da análise fatorial, tão aplicado atualmente nas mais diversas áreas da pesquisa científica, além de sugerir uma hipótese de investigação fecunda para a história das ciências: o papel da pesquisa em Psicologia para o desenvolvimento de métodos e técnicas apropriados e aplicados em outros campos do conhecimento, inclusive de métodos estatísticos de aplicação geral.

Depreende-se do que foi exposto o esforço empreendido para definir o conceito de inteligência, de uma perspectiva psicológica. A par da importância desse desenvolvimento para a história da Psicologia e das ciências em geral, à época e em períodos posteriores, o rigor da mensuração do conceito sofreu, especialmente por parte de educadores, restrições relevantes, entre as quais se destaca aquela referente ao fato de que as provas de inteligência incidem sobre produtos psicológicos superiores ou categorias psicológicas amadurecidas, não avaliam as condições de saída da aprendizagem ou pouco auxiliam na avaliação da inteligência quando ela não está ainda desenvolvida, posto que as provas são condicionadas pelos conteúdos que visam medir. A preocupação de Spearman é, como se procurou evidenciar, mais de natureza epistemológica voltada para a mensuração da inteligência da ótica psicológica, desembaraçando-a da biologia e da filosofia, ao mesmo tempo em que a propugna como uma aptidão "natural" dos indivíduos, associada mas não dependente estrita da educação. Esse entendimento permite situar a distinção entre as provas psicológicas de inteligência e as provas pedagógicas, discutidas na próxima seção.

O desenvolvimento do conceito, bem como as múltiplas teorias da inteligência a ele associadas constituem um importante capítulo da história da Psicologia, 
diga-se, bastante explorado na literatura especializada. A título de exemplos, vejam-se os estudos de Lawler (1981), voltados à crítica do conceito, na medida em que ele está associado à hereditariedade e ao racismo, e de Patto (1996), que relaciona a psicologia e as provas padronizadas à introdução da Escola Nova no Brasil como um dos elementos explicativos da produção do fracasso escolar. Entretanto, reitere-se, as observações precedentes prestam-se especialmente para situar a distinção dos testes de inteligência ou de nível mental dos testes educacionais, tal como propôs Lourenço Filho (2008), a propósito da elaboração dos testes ABC, bem como as ponderações de Alves (1934) acerca dos limites das provas psicológicas na educação escolar.

\section{Mensuração psicológica, estatística e educação}

Um dos paradoxos da sociedade contemporânea é o apelo quase obsessivo à estatística como base para a tomada de decisões administrativas, políticas e científicas, acompanhado da repulsa militante à aplicação dos métodos estatísticos em pesquisa social. A crença cega que diversas tendências das ciências sociais depositam na quantificação não fica em situação mais favorável do que a rejeição, igualmente cega, à mensuração, em nome de uma qualidade abstrata dos objetos sociais. Tal paradoxo está associado às disputas de métodos das ciências sociais, diga-se, muitas vezes cansativas, mas inevitáveis, em virtude da consequência política que carregam. Esse entendimento justifica o esforço empregado para apontar, em especial, os modos de aplicação da estatística à educação, a fim de proceder à avaliação psicológica e pedagógica do aluno. Para explorar a hipótese de que a ambiguidade relativa aos métodos quantitativos é uma das contradições da ideologia da racionalidade tecnológica imanente à sociedade administrada, destaca-se, aqui, a adoção dos testes psicológicos e educacionais como um dos fundamentos da organização pedagógica da escola primária brasileira, nos anos de 1930. Antes, porém, apresentamos duas breves ponderações para melhor situar a análise subsequente.

A primeira, de caráter geral, é importante para situar a posição aqui assumida a propósito da mensuração e avaliação psicológica. Espera-se justificar que a escola sob medida, admitida como uma premissa liberal, é verdadeira e falsa. O argumento principal dessa justificativa pode ser enunciado nos seguintes termos: sob a denominação de avaliação psicológica permanecem abrigados assuntos e métodos tão diversos e controversos, tais como os testes psicológicos padronizados (de nível mental, personalidade, inventários de interesse), entrevistas, escalas de atitudes, modelos de psicodiagnóstico, para mencionar alguns deles. Do ponto de vista técnico, a avaliação psicológica refere-se tanto aos instrumentos de aferição das variáveis psicológicas, quanto aos resultados e às consequências da aplicação 
desses instrumentos, seja para aceitá-los, seja para refutá-los, conforme a situação. Assim entendida, "a avaliação psicológica implica a elaboração ou escolha de instrumentos, aplicação e análise de resultados; portanto, implica o que aferir, como aferir e as consequências da aferição, ou seja, é propriamente um processo. É um equivoco visualizá-la tão somente como geradora de produto" (Sass, 2000a, p. 5; grifos no original). Nessa medida, a objetividade de que é revestida a avaliação psicológica parece ocultar a sua função política à medida que, em qualquer caso, trata-se de avaliar pessoas e tomar decisões por elas. Em decorrência disso, parece "plausível analisar os procedimentos técnicos da Psicologia, que, em nome de 'compreender' aquilo que está sob a pele do indivíduo, atuam de maneira flagrante para adaptá-lo às condições sociais objetivas (...)” (Sass, 2000a, p. 6). A análise minuciosa das técnicas psicológicas, assim como de seus usos, pode contribuir para evidenciar que a Psicologia como ciência aplicada converte-se em tecnologia, fomentando a conversão dos meios em fins. Esse entendimento, sustentado pelos estudos sistemáticos da teoria crítica da sociedade, permite a seguinte consideração: "se as técnicas psicológicas e sociológicas reduzem os indivíduos a aspectos e fatores, tipificando-os, é porque a sociedade em que vivem já os tipifica. A redução operada pelos instrumentos deveria, ao ensejar a crítica da técnica, ensejar também a crítica da sociedade que promove tal redução" (idem, ibid.). Nesses termos, há de evitar a crença cega por vezes depositada nas técnicas das ciências sociais, tanto quanto a recusa militante que supõe ser inútil ou insignificante a crítica imanente da técnica e da tecnologia. É dispensável insistir que, mutatis mutandis, as considerações expostas são generalizáveis para a esfera da avaliação da educação escolar, tal como se pretende mostrar mais à frente.

Registre-se, em segundo lugar, o interesse contemporâneo crescente, constatável nas duas últimas décadas, pelos usos da estatística na Educação e, em particular, por sua aplicação aos processos de produção de indicadores educacionais, mediante a avaliação da eficiência e eficácia das redes públicas de ensino, que alcança, hoje, desde a educação infantil até o ensino superior (Brasil, 2002). Registre-se ainda que está em andamento a criação do "sistema nacional articulado de educação" (CONAE, 2010) - impulsionado em boa dose pelos discutíveis resultados "positivos" obtidos pelo ensino brasileiro -, o qual inclui entre as suas 26 (de $a$ a $z$ ) provisões a seguinte: “d) A implantação de sistema nacional de avaliação da educação básica e superior para subsidiar o processo de gestão educativa e para garantir a melhoria da aprendizagem e dos processos formativos" (CONAE, 2010, 2009, p. 22). Claro está que o interesse contemporâneo pelo uso das estatísticas não guarda correspondência direta com os meios de avaliação educacional adotados nas primeiras décadas do século passado; contudo, é igualmente lícito admitir que a história dos métodos e finalidades correntes pode ser mais bem compreendida, caso se retroaja aos métodos e finalidades pretéritos da avaliação educacional. 
Mencione-se, de plano, que a finalidade dos métodos estatísticos aplicados até as primeiras décadas do século xx voltou-se mais para os recenseamentos escolares, a aferição da rede física de escolas, a organização pedagógica (seleção de alunos e organização de classes homogêneas, avaliação do nível mental e curvas de aprendizagem), a implementação da pedagogia experimental e administração escolar (contagem de matrículas, conclusões, deserção escolar, magistério, inspetoria escolar, entre outros) (Lourenço Filho, 2002), ao passo que, atualmente, a ênfase recai sobre a avaliação institucional, aferida pela eficiência das redes de ensino e eficácia das unidades escolares; caso em que o rendimento dos alunos é tomado como um dos indicadores de avaliação dos "sistemas".

Retomando o fio da meada, as provas padronizadas em educação são discutidas a seguir, com base nas proposições de Isaias Alves e Lourenço Filho, quanto às semelhanças e diferenças dos testes psicológicos e dos testes educacionais. Esse procedimento permite discutir duas consequências importantes dos testes psicológicos em educação: a interferência da psicologia na determinação dos fins da educação e a condição de aplicação das provas psicotécnicas (a qualidade do instrumento de avaliação e o preparo do professor como fator do sucesso da técnica).

\section{Testes psicológicos e testes educacionais.}

Em Introdução ao estudo da Escola Nova, Lourenço Filho destaca a Psicologia como a disciplina que há de proporcionar os recursos necessários para as duas faces da organização escolar, a saber: a estática, que recorre à genética e à psicologia das diferenças individuais, em especial, aos meios objetivos de verificação das semelhanças e diferenças entre os indivíduos - ou seja, recorre aos testes -, e a dinâmica, que exige a articulação entre a pedagogia experimental, a psicologia educacional e a filosofia (fundamentada na ciência psicológica) (Lourenço Filho, 1948).

Ora, a decorrência principal desse entendimento é que a psicologia científica, baseada na experimentação, passa a influir não somente sobre os meios da educação - tal como propugnavam Johan Herbart, no século xIX, e John Dewey, no século xx (cf. Sass, 2000b) -, como também passa, agora, a influir sobre os fins da educação, pois, como não mais se pode conceber uma "filosofia que despreze a ciência, verificase desde logo que a psicologia vai influir duplamente nas concepções da pedagogia: indiretamente, esclarecendo os problemas dos fins, através da filosofia; diretamente, fornecendo princípios da ciência pura, para aplicação prática, para a técnica educativa, propriamente dita" (Lourenço Filho, 1948, p. 34; grifos e grafia do original).

Em virtude de sua relevância, esse ponto deve ser reiterado. A psicologia passa a ser entendida como a disciplina que interfere nos fins da educação, porque 
subsidia a "nova" filosofia pautada pela ciência experimental, superando assim a "velha" filosofia do espírito. Contudo, se essa ruptura representa um passo necessário para que a psicologia intervenha na etapa dinâmica do ensino, ela não é suficiente, visto que a inflexão para a experiência do indivíduo condicionada "à descrição do comportamento individual pressupõe a experiência organizada (...)" (Lourenço Filho, 1948, p. 34). Esse excerto não deixa dúvidas quanto ao significado que atribui à experiência: ela é definida como atividade do sujeito organizada por condições mantidas sob controle externo a ele. Se, de fato, a maioria dos comportamentos individuais é submetida às condições externas, então é inexorável concluir que o impulso espontâneo característico do que se denomina como experiência é severamente abalado, ou, pelo menos, deve se expressar dentro da ordem externa.

Sustentando posição semelhante, Isaias Alves(1934) considera que a organização da experiência para bem descrever e analisar o comportamento deve admitir que a inteligência é a condição primeira do progresso dos alunos, mediante a aplicação individual de provas estandardizadas de inteligência, a fim de garantir um progresso escolar apropriado às suas potencialidades e limitações:

Admitindo que a primeira condição do progresso escolar de um menino é um gráu de inteligencia que lhe permita, sem cansaço, seguir o curriculum escolar, chegaremos á conclusão higienica e sociologica: todo curso escolar em que não se consulta a possibilidade intelectual do aluno é apenas fábrica de nervosos, de instaveis de despersonalizados, de ambiciosos inadaptáveis ou desalentados ratés em qualquer profissão. (Alves, 1934, p. 187; grifos e grafia do original)

Como se vê, de acordo com Alves, a medida necessária para se evitar que a escola seja uma fábrica de nervosos e desajustados é a média da inteligência, aferida em testes padronizados. Todavia, para o referido autor, a aferição da inteligência do aluno não é tudo; a importância dos testes de inteligência deve ser atribuída ao fato de que eles "(...) não são para avaliar a capacidade dos meninos normalmente desenvolvidos, mas para salvar os que se atrasam por motivos alheios aos seus dotes" (Alves, 1934, p. 10).

Para o que aqui interessa, mais importante do que considerar a confiança salvadora depositada no teste de inteligência que resultou em seu contrário, como a história veio mostrar, à medida que serviu e serve de mecanismo de exclusão social e escolar, ressalte-se, de um lado, a sua aplicação para graduar o ensino, dosando-o adequadamente a cada um e a todos, e para compor classes homogêneas, de sorte a evitar o ajuntamento de crianças com potenciais discrepantes (Alves, 1934, p. 187 e ss.); de outro lado, a exigência de que elas sejam complementadas pelo acompanhamento sistemático do desempenho escolar do aluno, de incumbência do professor, por meio do teste educacional ou pedagógico, "que não é mais do que uma 
prova escrita de forma definida, oferece garantia e facilidade de verificação semanal ou quinzenal, impossível no sistema tradicional" (Alves, 1934, p. 12), isto é, aquele sistema baseado apenas em provas escritas realizadas de tempos em tempos, sem critérios bem definidos.

Não há como se confundir: os testes psicológicos, cuja aplicação é uma atribuição do professor - não de médicos ou psicologistas -, incidem sobre a inteligência, a fim de avaliar o aluno ingressante, graduar o ensino, compor classes homogêneas, bem como sobre o aproveitamento escolar. Em termos mais precisos, este é também o entendimento de Lourenço Filho, como se depreende do seguinte excerto:

Do ponto de vista escolar, êsses mesmos processos científicos de organização dos testes psicológicos (base estatística e técnica de aplicação) vieram fornecer elementos para a organização da medida objetiva de todo o trabalho do mestre. Ao lado dos testes psicológicos, lança mão a pedagogia moderna dos testes pedagógicos ou de escolaridade. São meios, igualmente simples, pelos quais se pode verificar o andamento do ensino, e proceder-se assim à comparação objetiva entre o trabalho dos professôres de duas classes (...)" (Lourenço Filho, 1948, p. 31-32; grifos do original)

Se os testes psicológicos são importantes ao início do ensino, os testes escolares são decisivos para a verificação da eficiência do que é ensinado. Como meios, os testes educacionais:

(...) vieram permitir a organização de normas de uma verdadeira pedagogia experimental, cujas conquistas são de grande alcance para a economia da administração. Mas, não são processos de ensino: são meios de verificação.

Se os testes psicológicos intervêm, como dissemos, antes do ensino, podemos dizer agora que os testes pedagógicos se empregam depois dêle. Intervindo antes do ensino ou depois dêle, é claro que os testes não influem diretamente, e por si sós, na técnica didática. Podem, é certo, fornecer elemento de maior clareza para úteis transformações dos processos em uso, substituindo o critério do julgamento dos mestres e administração, pelo critério objetivo dos fatos. (Lourenço Filho, 1948, p. 32; grifos e grafia do original)

Um bom exemplar da diferenciação entre os dois tipos de teste é encontrado em Testes ABC, de Lourenço Filho (2008), elaborados no final dos anos de 1920 e publicados em várias edições, desde 1931. Aqui são destacados dois aspectos dessa prova padronizada, com o intuito de reiterar o caráter tecnológico da psicologia, conforme a definição apresentada no início.

É de se ressaltar o subtítulo adequado escrito pelo autor, após o título Testes $\mathrm{ABC}$ : "para a verificação da maturidade necessária à aprendizagem da leitura e da escrita" (Lourenço Filho, 2008), pois ele sintetiza dois elementos importantes da mensuração psicológica. Primeiro, visa a esclarecer que o teste não deve ser confundido com as escalas de inteligência, usuais à época. Segundo, vincula-se aos meios 
da educação na medida em que está voltado para a verificação da maturidade para o aprendizado da criança que ingressa na escola. Contudo, essa proposição não contraria aquela, antes transcrita, pela qual o educador sustenta que o teste psicológico deve preceder o ensino, enquanto o teste pedagógico acompanha o aproveitamento escolar? Se o teste АBC é de verificação da maturidade para aprender a ler e escrever, não há de ser, pela definição do autor, um teste pedagógico? No entanto, como ele deve ser aplicado a cada criança antes do ensino, não é mais apropriadamente um teste psicológico?

Para responder adequadamente a essas indagações é imprescindível analisar a hipótese submetida à prova, tanto pelo educador como por outros pesquisadores brasileiros e de outras nacionalidades. Para formulá-la, Lourenço Filho evidencia dois problemas até então não resolvidos, seja pelo empirismo que orientava boa parte das práticas educacionais, com a adoção do critério insuficiente de idade cronológica, de 6 a 7 anos, como suposto para a alfabetização, seja pelo critério de quociente de inteligência (QI) obtido pela relação proporcional entre idade mental - desempenho aferido em provas padronizadas de nível mental - e idade cronológica, geralmente medida em meses. Se há de se reconhecer o progresso e a extensa aplicação da idade mental na educação, ao fornecer um diagnóstico precoce do potencial de aprendizagem, na medicina, à medida que identifica "anormalidades", bem como na orientação profissional, é irrefutável igualmente que, encarando o assunto do ponto de vista da organização escolar, "A verdade é que a simples classificação pela idade mental, ou mesmo segundo a relação entre essa idade e a idade cronológica (QI), não tem dado o resultado esperado em se tratando das classes de $1^{\circ}$ grau, ou seja, classes para o aprendizado inicial da leitura e escrita" (Lourenço Filho, 2008, p. 28; grifos no original); nem o critério da idade cronológica, por sua demasiada abstração, nem o critério de inteligência, por causa das exigências das provas, quase sempre verbais e de habilidades mais complexas, já estruturados pelo sujeito, obtiveram êxito. Os resultados até então obtidos em reiteradas pesquisas mostravam baixa correlação entre idade cronológica e desempenho escolar, assim como não mostravam a suposta correlação alta entre inteligência e capacidade para ler e escrever (Lourenço Filho, 2008, p. 28 e ss.).

Para aferir com rigor as condições da aprendizagem escolar inicial, é forçoso concluir que "(...) o aprendizado central dos primeiros graus, o da fase inicial da leitura, exige não um mínimo de linguagem, mas um mínimo de maturidade expressa por coordenação visual-motora e auditivo-motora da palavra, de atenção e fatigabilidade" (Lourenço Filho, 2008, p. 28). Daí a hipótese principal do teste ABC, submetida à prova em duas partes: na determinação de certo nível de maturidade necessário à aprendizagem da leitura e da escrita não há correlação entre o nível obtido e a idade cronológica, assim como não há correlação daquele com a idade mental ou o quociente de inteligência (Lourenço Filho, 2008). 
Apesar da ambiguidade que contém a distinção entre testes psicológicos e educacionais, o teste $\mathrm{ABC}$ é qualificado como de natureza psicológica, em virtude das variáveis psicológicas mensuradas (forma final: coordenação visual motora, resistência à inversão psicomotora, memorização visual, coordenação auditivo-motora, capacidade de prolação, resistência à ecolalia, memorização auditiva, fatigabilidade, atenção dirigida, vocabulário e compreensão), por meio de oito testes, aplicados individualmente em uma sessão, pelo professor. De outra parte, como meio de verificação disponível para avaliar o andamento do processo de ensino, ele é um instrumento do professor, que, obviamente, deve estar bem preparado para fazer um bom uso do teste. Planejado para medir o nível de maturidade dos alunos ingressantes na escola primária, o teste $\mathrm{ABC}$ serve de diagnóstico das condições de maturidade para a aprendizagem de cada aluno; em suma, permite ao professor a obtenção do diagnóstico individual, bem como serve de critério para a organização de classes seletivas, compostas de alunos em níveis não muito distantes de maturidade, decorrendo daí a sua natureza diagnóstica. Embora permaneçam diferenças acerca da distinção entre os tipos e natureza dos testes em educação propostas por Isaias Alves e Lourenço Filho, não é aqui o lugar de aprofundar a discussão.

O outro aspecto a ser destacado é relativo aos destinatários do livro. Três características aí sobressaem: $1^{\underline{a}}$ ) redigido em linguagem precisa, o texto apresenta as principais etapas de validação do teste, dosando a recorrência à terminologia da estatística e cuidando de esclarecer os principais conceitos de uma técnica razoavelmente complexa, supõe-se, para o professor primário. Acrescente-se a isso que expõe de maneira clara e sucinta a crítica das pesquisas acerca do problema da investigação e a lógica da elaboração do teste; $2^{\underline{a}}$ ) embora seja passível de crítica do especialista por causa de omissões ou discutíveis considerações relativas à validade estatística de suas afirmações, contornáveis por métodos de inferência estatística, disponíveis à época, é de se supor que a decisão do autor tenha sido orientada não pelo desconhecimento desses métodos, mas porque ele elegeu como principal destinatário o professor e os dirigentes da escola primária. É o que se conclui quando se observa os capítulos dedicados ao escopo de aplicações da prova (cf. Lourenço Filho, 2008); $3^{3}$ ) por essas duas características é que o teste $\mathrm{ABC}$ pode ser considerado um exemplar da racionalidade tecnológica, que exige a técnica, o aparato social e institucional para produzi-la e o sujeito adaptado - o professor - para colocá-la em prática.

\section{Considerações finais}

Mais do que apresentar resultados irrefutáveis, procurou-se aqui consubstanciar a hipótese de que a relação entre a psicologia e a estatística, no campo educacional, não se esgota com a explicação do progresso científico inexorável; tal relação 
pode ser explicada também e principalmente pela racionalidade tecnológica, característica da sociedade industrial e administrada. Apontou-se essa perspectiva por meio da psicotécnica, primeiramente, repondo um momento importante do desenvolvimento da noção de inteligência, exemplificada pela teoria dos dois fatores de Spearman; depois, por meio da aplicação de testes psicológicos e educacionais, na escola primária brasileira, conforme os educadores Isaias Alves e Lourenço Filho.

Espera-se ter evidenciado a relevância de se investigar as aplicações educacionais da estatística e da psicologia para além de suas especificidades técnicas, de modo a incluir o aparato institucional e o sujeito indispensavelmente adaptado à tecnologia que movimenta e reproduz aquela racionalidade. Ao final das contas, como a teoria crítica tem evidenciado com consistência: crítica do conhecimento é crítica da sociedade e vice-versa.

\section{Nota}

1. Utiliza-se aqui a tradução espanhola: Las habilidades del hombre (1954), cujos excertos traduzidos para o português são de minha responsabilidade. A relevância da teoria bifatorial da inteligência de Spearman para o desenvolvimento da Análise Fatorial, hoje aplicada às mais distintas áreas da pesquisa empírica e experimental e aos ramos de negócios, é discutida por Guilford (1954).

\section{Referências}

ALVES, I. Os testes e a reorganização escolar. 2. ed. Rio de Janeiro: Industria do Livro, 1934.

BERNSTEIN, J. La psicologia factorial de Spearman. In: SpeArman, C. Las habilidades del hombre: su naturaleza y medición. Buenos Aires: Paidós, 1954. p. 11-21.

BRASIL. Ministério da Educação. Instituto Nacional de Estudos e Pesquisas Educacionais (INEP). Geografia da Educação Brasileira. Brasília, DF: MEc/INEP, 2002.

CLAPARÈDE, E. A escola sob medida. Rio de Janeiro: Fundo de Cultura, 1973.

CONFERENCIA NACIONAL DE EDUCAÇÃO (CONAE), 2010, Brasília, DF. Construindo o Sistema Nacional Articulado de Educação. Brasília, DF: ConAE/MEC, 2009.

GARRET, H.E. Grandes experimentos da psicologia. 3. ed. São Paulo: Nacional, 1974.

GUILFORD, J.P. Psychometric methods. 2. ed. New York: McGraw-Hill, 1954.

LAWLER, J. Inteligência, hereditariedade e racismo. Lisboa: Caminho, 1981.

LEITE, D.M. Psicologia diferencial e estudos em educação. São Paulo: unesP, 2008. 
LOURENÇO FILHO, M.B. Introdução ao estudo da Escola Nova. 6. ed. São Paulo: Melhoramentos, 1948.

LOURENÇO FILHO, M.B. Tendências da educação brasileira. Organizadores Ruy Lourenço Filho e Carlos Monarcha. 2. ed. Brasília, DF: INEP/MEC, 2002.

LOURENÇO FILHO, M.B. Testes $A B C$ : para a verificação da maturidade necessária à aprendizagem da leitura e da escrita. 13. ed. Brasília, DF: INEP, 2008.

MARCUSE, H. A ideologia da sociedade industrial: o homem unidimensional. 5. ed. Rio de Janeiro: Zahar, 1979.

MARCUSE, H. Tecnologia, guerra e fascismo. Editado por Douglas Kellner. São Paulo: UNESP, 1999.

PATTO, M.H.S. A produção do fracasso escolar: histórias de submissão e rebeldia. 4. ed. São Paulo: T.A. Queiroz, 1996.

SASS, O. O lugar da avaliação psicológica. In: Pellini, M.C.M. Avaliação psicológica para porte de arma de fogo: contribuições da prova de Rorschach. São Paulo: Casa do Psicólogo, 2000a. p. 5-9.

SASS, O. Educação e psicologia social: uma perspectiva crítica. São Paulo em Perspectiva, São Paulo, v. 14, n. 2, p. 57-64, 2000b.

SPEARMAN, C. "General intelligence" objectively determined and measured. American Journal of Psychology, New York, n. 15, p. 201-293, 1904.

SPEARMAN, C. Las habilidades del hombre: su naturaleza y medición. Buenos Aires: Paidós, 1954.

Recebido em 30 de julho de 2010.

Aprovado em 27 de novembro de 2010. 